\title{
ПРЕВЕНТИВНАЯ ПСИХИАТРИЯ
}

УДК 616.891.6:616.895.4:616.89-008.441.13:616.89-008.441.33:65.012.124-028.51:378.17-057.875(571.16)

Для цитирования: Бохан Н.А., Воеводин И.В., Лукьянова Н.А., Пушкаренко А.Б. Аддиктивные и тревожно-депрессивные расстройства у студентов Томской области: динамика, половозрастной и миграционный аспекты. Сибирский вестник психиатрии и наркологии. 2017; 3 (96): 38 —45. https://doi.org/10.26617/1810-3111-2017-3(96)-38-45

\section{Аддиктивные и тревожно-депрессивные расстройства у студентов Томской области: динамика, половозрастной и миграционный аспекты}

\author{
Бохан Н.А. ${ }^{1,2}$, Воеводин И.В. ${ }^{1,3}$, Лукьянова Н.А. ${ }^{4}$, Пушкаренко А.Б. \\ ${ }^{1}$ Научно-исследовательский институт психического здоровья \\ Томский национальный исследовательский медииинский центр Российской академии наук \\ Россия, 634014, Томск, ул. Алеутская, 4 \\ ${ }^{2}$ Сибирский государственный медииинский университет \\ Россия, 634050, Томск, Московский тракт, 2 \\ ${ }^{3}$ Национальный исследовательский Томский государственный университет \\ Россия, 634050, Томск, пр. Ленина, 36 \\ ${ }^{4}$ Начиональный исследовательский Томский политехнический университет \\ Россия, 634050, Томск, пр. Ленина, 30 \\ ${ }^{5}$ Администрация Томской области \\ Россия, 634050, Томск, пл. Ленина, 6
}

\section{PEЗЮME}

Цель исследования - оценка актуального состояния и динамики психического здоровья студентов вузов (распространенности аддиктивных и тревожно-депрессивных расстройств). Материал и методы: проанализированы результаты трех исследований методом анонимного анкетирования (2015, 2011 и 2003 гг.), обследовано 22 060, 669 и 657 человек соответственно. Результаты: в 2015 г. распространенность среди студентов курения табака составила 34,8\%, злоупотребления алкоголем $-19,6 \%$, опыта употребления наркотиков - 10,6\%, тревоги $-27,3 \%$, депрессии - 15,6\%. Ведущие тенденции динамики - феминизация наркотизма, снижение значимости субмиссивной мотивации и возрастание значимости атарактической мотивировки потребления психоактивных веществ. Обоснованы подходы к дифференцированной профилактике аддиктивных и тревожно-депрессивных состояний в вузах.

\section{Ключевые слова: студенты, психическое здоровье, употребление психоактивных веществ, тревога, депрессия.}

\section{ВВЕДЕНИЕ}

Для осуществления мероприятий по профилактике зависимостей требуются стратегии, учитывающие социальные, культуральные и экономические особенности отдельных целевых групп [14]. Необходим единый, научно обоснованный подход к стандартизации и оценке программ, обеспечивающий внедрение наиболее эффективных профилактических интервенций для дифференцированных групп населения [12]. Одной из таких групп выступают студенты и молодые специалисты [13]. В совместной работе сибирских психиатров отмечается, что особое значение профилактика аддиктивного поведения и зависимостей среди высокообразованной молодежи имеет в регионах, где научнообразовательный комплекс наиболее развит и имеет ведущее значение в экономике; к числу таких регионов в Сибирском федеральном округе относится Томская область [7].

Цель исследования - оценка психического здоровья студентов вузов (изучение распространенности аддиктивных и тревожно-депрессивных расстройств), а также динамики его показателей, влияния на показатели половозрастного и миграционного факторов.

\section{МАТЕРИАЛЫ И МЕТОДЫ}

Проанализированы данные масштабного межвузовского исследования, осуществленного по заказу Администрации Томской области специалистами и волонтерами Томского политехнического университета по методикам НИИ психического здоровья. Исследование охватило 9 вузов Томской области, в нём приняли участие 22060 студентов.

В обследованной выборке преобладали девушки (55,0\%), средний возраст студентов составил $20,1 \pm 1,8$ года. Студенты I курса составили $27,8 \%$, II курса - 22,8\%, III курса - 20,2\%, IV курса - 15,2\%, $\mathrm{V}$ курса и магистратуры - $13,6 \%$ обследованных; 0,4\% - не указали курс обучения. 35,5\% обследованных проживали до поступления в Томске, $15,9 \%$ - прибыли на учебу из районов Томской области, $33,8 \%$ - из других регионов России, 14,7\% - из зарубежных государств (Казахстан, Узбекистан, Киргизия и др.), 0,1\% опрошенных не указали региона проживания до поступления в вуз.

Для оценки динамики ситуации проведен сравнительный анализ данных трех контрольных точек, характеризующих разные периоды наркологической ситуации. 
Первая контрольная точка включала исследование 2003 г., когда на рынке наркотиков Томской области завершился переход от кустарных опиоидов к героину. Вторая точка - исследование 2011 г., этап ослабления на рынке позиций героина и растительных каннабиноидов, поискового полинаркотизма («аптечные наркотики», «соли» и др.), начало бурного распространения синтетических каннабиноидов. Третья точка - основное исследование 2015 г., когда ситуацию на рынке и среди потребителей в наибольшей степени определяли синтетические каннабиноиды.

В первой контрольной точке обследовано 657 студентов, во второй точке - 669. В обеих выборках преобладали девушки $(66,7 \%$ и $62,3 \%$ соответственно), средний возраст составил $18,9 \pm 1,3$ и 20,1 $\pm 1,6$ года.

Исследование в 2015 г. проводилось методом анонимного анкетирования по анкете, разработанной в НИИ психического здоровья и позволяющей получать результаты, корректные для сравнительного анализа с результатами прошлых исследований. Были оценены такие параметры: рейтинг наиболее актуальных для современных студентов проблем, вовлеченность в употребление табака, злоупотребление алкоголем и опыт употребления наркотиков, мотивировки употребления психоактивных веществ, тревожно-депрессивная симптоматика (по методике «Госпитальная шкала тревоги и депрессии» - Hospital Anxiety and Depression Scale).

\section{РЕЗУЛЬТАТЫ И ОБСУЖДЕНИЕ}

В первую очередь был оценен показатель «Рейтинг проблем, наиболее актуальных для современных студентов» (табл. 1).

Сгруппировав и проанализировав указанные студентами проблемы, можно отметить, что в качестве наиболее актуальных выступали проблемы материально-бытовые, на них пришлось 20,8\% в общем рейтинге.

Средняя степень выраженности выявлена для проблем с учебой и будущей специальностью $(16,5 \%)$, проблем низкой культуры в студенческой среде $(14,4 \%)$, химических аддикций $(12,9 \%)$, коммуникативных проблем $(12,4 \%)$, нехимических аддикций $(11,2 \%)$.

Меньшую озабоченность вызывают у студентов проблемы физического здоровья $(4,6 \%)$, девиантного поведения $(3,7 \%)$ и проблема «нервных срывов» $(3,5 \%)$.

Динамика актуальных проблем оценена путем сравнительного анализа с результатами аналогичного опроса 2011 г;; статистически достоверные различия проиллюстрированы на рисунке 1.

Наиболее значимый рост выявлен для значимости проблемы нехимических аддикций $(11,2 \%$ в общем рейтинге vs 6,9\% в 2011 г., p<0,01), также обнаружена тенденция возрастания в студенческой среде значимости проблем с учебой и выбором будущей специальности, бескультурия и девиантного поведения.
Т а б л и ц а 1

Рейтинг наиболее актуальных проблем Проблема

\begin{tabular}{|c|c|c|c|}
\hline Проблема & $\begin{array}{c}\text { Число } \\
\text { указаний } \\
\text { на акту- } \\
\text { альность } \\
\text { проблемы }\end{array}$ & $\begin{array}{c}\text { \% счита- } \\
\text { ющих } \\
\text { проблему } \\
\text { актуаль- } \\
\text { ной }\end{array}$ & $\begin{array}{c}\text { Доля } \\
\text { проблемы } \\
\text { в общем } \\
\text { рейтинге } \\
\text { проблем }\end{array}$ \\
\hline Бытовые и материальные трудности & 7440 & 33,7 & 11,7 \\
\hline Высокие учебные нагрузки & 6304 & 28,6 & 9,9 \\
\hline $\begin{array}{l}\text { Необходимость зарабатывать день- } \\
\text { ги параллельно с обучением в вузе }\end{array}$ & 5755 & 26,1 & 9,1 \\
\hline $\begin{array}{l}\text { Компьютерная и Интернет-зависи- } \\
\text { мость, виртуальная реальность }\end{array}$ & 5534 & 25,1 & 8,7 \\
\hline $\begin{array}{l}\text { Бескультурие (несоблюдение нрав- } \\
\text { ственных норм, употребление не- } \\
\text { цензурных слов, духовная бедность) }\end{array}$ & 5180 & 23,5 & 8,2 \\
\hline $\begin{array}{l}\text { Отсутствие перспектив трудо- } \\
\text { устройства по специальности }\end{array}$ & 4198 & 19,0 & 6,6 \\
\hline Утрата целей, ценностей, интереса к жизни & 3959 & 17,9 & 6,2 \\
\hline $\begin{array}{l}\text { Взаимоотношения со старшими по } \\
\text { возрасту и статусу (родители, пре- } \\
\text { подаватели, администрация вуза) }\end{array}$ & 3648 & 16,5 & 5,7 \\
\hline Курение табака & 3319 & 15,0 & 5,2 \\
\hline \begin{tabular}{|l} 
Пьянство, в том числе \\
злоупотребление пивом
\end{tabular} & 2953 & 13,4 & 4,6 \\
\hline Физическое здоровье & 2919 & 13,2 & 4,6 \\
\hline $\begin{array}{l}\text { Взаимоотношения с любимым } \\
\text { человеком } \\
\end{array}$ & 2529 & 11,5 & 4,0 \\
\hline $\begin{array}{l}\text { «Нервные срывы» и другие психи- } \\
\text { ческие расстройства }\end{array}$ & 2236 & 10,1 & 3,5 \\
\hline Употребление наркотиков & 1941 & 8,8 & 3,1 \\
\hline Взаимоотношения со сверстниками & 1727 & 7,8 & 2,7 \\
\hline Азартные игры, игровые автоматы & 1616 & 7,3 & 2,5 \\
\hline $\begin{array}{l}\text { Сексуальная распущенность } \\
\text { в студгородках }\end{array}$ & 1271 & 5,8 & 2,0 \\
\hline $\begin{array}{l}\text { Правонарушения, } \\
\text { асоциальное поведение }\end{array}$ & 1051 & 4,8 & 1,7 \\
\hline
\end{tabular}

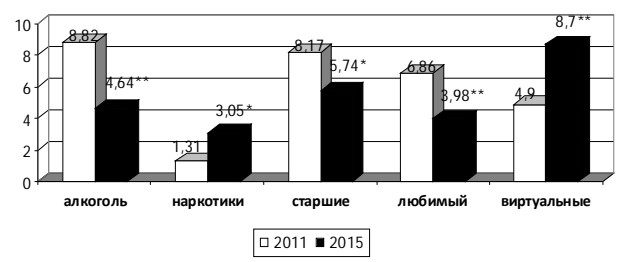

Рисунок 1 - Динамика удельного веса наиболее актуальных для студентов проблем, \%

Примечание: $* *-p<0,01 ; *-p<0,05)$

Наиболее значимо снизилась роль проблем в коммуникациях (12,4\% vs 18,0\% в 2011 г., р<0,01), также проявились тенденции снижения значимости материально-бытовых проблем, проблем физического и психического здоровья.

Разнонаправленные тенденции обнаружили составляющие показателя химических аддикций снижение обеспокоенности проблемой алкоголизации и рост беспокойства по поводу проблемы наркотиков. Юноши чаще отмечают проблемы с химическими и нехимическими аддикциями (алкоголь, табак, наркотики, виртуальная аддикция и азартные игры), целями и ценностями. Девушки больше обеспокоены проблемами с психическим и физическим здоровьем, со старшими, с учебными нагрузками и перспективами трудоустройства. 
Для студентов младших курсов большее значение имеют учебные нагрузки, цели и ценности, для старшекурсников - необходимость подработки во время учебы и перспективы будущего трудоустройства.

Для студентов-томичей, проживающих преимущественно в родительских семьях, сравнительно более актуальной оказалась проблема подработки, для приезжих - проблема виртуальной аддикции.

Вторым проанализированным показателем стало «Употребление табака, злоупотребление алкоголем, опыт употребления наркотиков» (химические аддикции). Результаты представлены в таблице 2.

Т а б л и ц а 2

Вовлеченность студентов в аддиктивное поведение

\begin{tabular}{|l|c|c|}
\hline \multicolumn{1}{|c|}{ Психоактивное вещество: } & $\begin{array}{c}\text { абс. число } \\
\text { указаний }\end{array}$ & $\begin{array}{c}\text { \% от числа } \\
\text { обследованных } \\
\text { студентов }\end{array}$ \\
\hline Употребление табака & 7671 & 34,8 \\
\hline Злоупотребление алкоголем & 4324 & 19,6 \\
\hline Опыт употребления наркотиков & 2347 & 10,6 \\
\hline
\end{tabular}

Примечание. Оценены все указания на табакокурение, включая эпизодическое; указания на превышение уровня «нормативного» употребления алкоголя по критериям частоты и/или интенсивности алкоголизаций; все указания на наличие опыта употребления наркотиков, включая однократный).

Сравнение уровня употребления студентами табака с результатами исследования 2011 г. (в 2003 г. показатель не исследовался) обнаружило статистически сопоставимую картину, с незначительным преобладанием распространенности табакокурения среди юношей в обоих случаях.

Общая динамика распространенности злоупотребления алкоголем и её межполовые различия проиллюстрированы на рисунке 2.

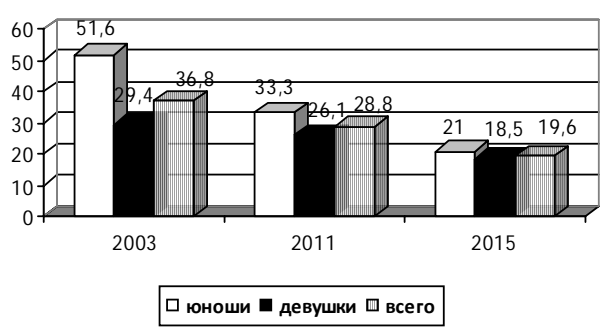

Рисунок 2 - Динамика распространенности злоупотребления алкоголем среди студентов, \%

Наблюдается общая тенденция к снижению уровня злоупотребления алкоголем, проявляющаяся среди юношей в большей степени и менее выраженная у девушек, с выраженным сглаживанием межполовых различий в динамике.

Динамика распространенности среди студентов наркотического опыта и межполовые динамические различия показателя представлены на рисунке 3 .

Уровень распространенности наркотического опыта среди студентов, достаточно стабильный (в среднем) на протяжении предыдущего десятилетия, в последнем исследовании обнаружил выраженную тенденцию к снижению.

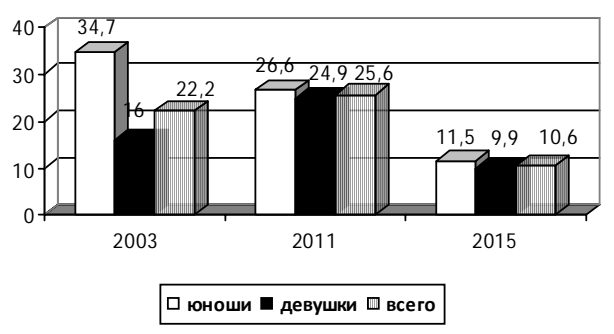

Рисунок 3 - Динамика распространенности опыта употребления наркотиков среди студентов, \%

При этом, как и в ситуации со злоупотреблением алкоголем, актуально уменьшение разрыва между уровнями вовлеченности в наркотизацию юношей и девушек, т.е. в обоих случаях наблюдается явная тенденция «феминизации» наркотизма. Установлено также, что возраст студентов и курс обучения не влияют достоверно ни на один из показателей потребления психоактивных веществ. Среди студентов-томичей выявлен сравнительно более высокий уровень употребления табака $(36,4 \%)$, среди студентов, прибывших из районов области, - уровень злоупотребления алкоголем $(21,6 \%)$, а среди студентов, прибывших из-за рубежа, - уровень наличия наркотического опыта (12,3\%).

Третий показатель - «Мотивировки употребления психоактивных веществ». В данном случае важен подход к классификации мотивов потребления психоактивных веществ. В литературе часто встречается подход зарубежный авторов [18], рассматривающий мотивы копинга (coping), социальные (social), иногда с отдельным выделением конформных (conformity), и активации (enhancement).

Наиболее распространенный отечественный подход, базирующийся на классификации В.Ю. Завьялова, предложенной еще в 1988 г. для алкогольной зависимости и не всегда корректно переносимой на зависимость наркотическую, включает другие три группы мотивов: социально-психологические (традиционные, субмиссивные, псевдокультурные), личностные (гедонистические, атарактические, гиперактивации) и патологические (абстинентные, аддиктивные, самоповреждения) [16]. Отсутствие единого общепринятого подхода к классификации мотивов потребления приводит к возникновению различных авторских подходов [15]. Среди них наиболее интересным и обоснованным представляется подход А.Ю. Егорова и др. (2006), рассматривающий 5 наиболее значимых мотивов обращения к психоактивным веществам. К ним авторы относят: гедонистический (включая любопытство), субмиссивный (заключающийся в конформном следовании традициям микросоциального окружения), коммуникативный (для облегчения общения), детензивный или атарактический (устранение неприятных эмоций) и протестно-демонстративный (сопротивление требованиям окружающих, например, «назло родителям») [11]. 
Наш подход в значительной степени пересекается с подходом А.Ю. Егорова, с дополнительным выделением мотивов гиперактивации (употребление «от скуки») и традиционного (в отличие от субмиссивного употребления, следования правилам непосредственного, микросоциального окружения, традиционное употребление подразумевает традиции общества в целом, макросоциума, окружения, не являющегося непосредственным, в связи с чем возможно только для легальных психоактивных веществ и невозможно для наркотиков) [10].

Результаты исследования мотивировок потребления представлены в таблице 3.

Т а б ли ц а 3

Мотивировки потребления психоактивных веществ

\begin{tabular}{|c|c|c|}
\hline Ведущий мотив & $\begin{array}{c}\text { Абс. число } \\
\text { указаний }\end{array}$ & $\begin{array}{c}\text { Доля моти- } \\
\text { вировки в } \\
\text { общем } \\
\text { рейтинге }\end{array}$ \\
\hline \multicolumn{3}{|c|}{ Мотивировка потребления табака } \\
\hline Гедонистическая & 3517 & 32,0 \\
\hline Атарактическая & 2994 & 27,3 \\
\hline Субмиссивная & 894 & 8,1 \\
\hline Протестно-демонстративная & 617 & 5,6 \\
\hline Гиперактивации & 2021 & 18,4 \\
\hline Традиционная & 941 & 8,6 \\
\hline \multicolumn{3}{|c|}{ Мотивировка потребления алкоголя } \\
\hline Гедонистическая & 5289 & 25,8 \\
\hline Атарактическая & 5080 & 24,8 \\
\hline Субмиссивная & 1119 & 5,5 \\
\hline Протестно-демонстративная & 678 & 3,3 \\
\hline Гиперактивации & 4564 & 22,3 \\
\hline Традиционная & 3731 & 18,2 \\
\hline \multicolumn{3}{|c|}{ Мотивировка потребления наркотиков } \\
\hline Гедонистическая & 1288 & 42,7 \\
\hline Атарактическая & 1003 & 33,3 \\
\hline Субмиссивная & 155 & 5,1 \\
\hline Протестно-демонстративная & 206 & 6,8 \\
\hline Гиперактивации & 363 & 12,0 \\
\hline
\end{tabular}

Динамика мотивировок употребления табака по сравнению с 2011 г. не обнаруживает статистически достоверных различий (в 2003 г. данный показатель не исследовался). Для алкоголя и наркотиков динамика мотивировок проиллюстрирована на рисунке 4.

Динамика мотивировок употребления алкоголя

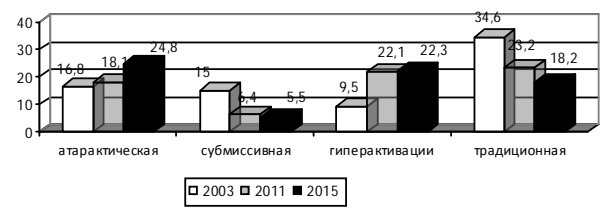

Динамика мотивировок употребления наркотиков

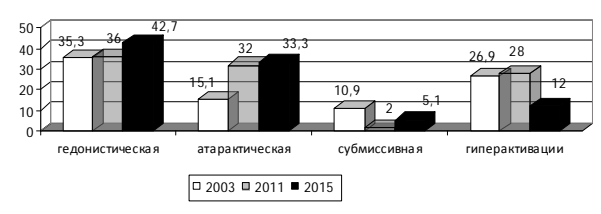

Рисунок 4 - Динамика мотивировок употребления алкоголя и наркотиков, \%
Наблюдается разнонаправленная динамика атарактических и субмиссивных мотивировок и неуклонное снижение значимости традиционной мотивировки алкоголизаций, свидетельствующее о сохраняющейся напряженности ситуации с употреблением ПАВ согласно нашим данным [6].

В группе девушек преобладают атарактические мотивировки во всех трех случаях (табак $-28,8 \%$ vs $25,6 \%$ у юношей, $\mathrm{p}=0,0001$; алкоголь - 26,8\% vs $22,6 \% \mathrm{p}=0,0000$; наркотики - $38,5 \%$ vs 28,5 , $\mathrm{p}=0,0000)$. Для студентов младших курсов в большей степени характерны атарактическая и субмиссивная мотивировки, ко II и III курсу возрастает значение гиперактивации и роль протестнодемонстративной мотивации, с IY курса доминирует гедонистический мотив (характерно для всех трех субстанций). При сравнительном анализе в группах местных студентов и студентов-мигрантов отмечается преобладание протестной мотивировки потребления алкоголя среди прибывших из зарубежных республик (как правило, среднеазиатских, со значимым влиянием мусульманских традиций, в том числе негативного отношения к алкоголю).

Четвертым проанализированным показателем стала «Распространенность клинической и субклинической тревоги и депрессии среди студентов». А.О. Бухановский и др. (2012) в обзоре зарубежной литературы отметили множество данных о коморбидности химических и нехимических зависимостей с расстройствами настроения, тревогой и депрессией [8]. Аналогичные результаты получены в ряде исследований томских психиатров [1, 2, 3, 4].

Результаты изучения специалистами НИИ психического здоровья психодезадаптационных состояний [17] свидетельствуют о прямом или опосредованном психогенном происхождении невротических и аддиктивных состояний, их родстве - как на этапах раннего формирования, по механизмам «невротизации», так и в ходе последующей клинической динамики.

Уровни распространенности тревоги и депрессии среди студентов представлены в таблице 4.

Т а б ли и ц 4

Распространенность клинической и субклинической тревоги и депрессии среди студентов

\begin{tabular}{|c|c|c|}
\hline Симптоматика & Абс. число указаний & $\begin{array}{c}\% \text { от числа } \\
\text { обследованных }\end{array}$ \\
\hline Тревога & 6026 & 27,3 \\
\hline Депрессия & 3444 & 15,6 \\
\hline
\end{tabular}

На рисунке 5 отражена динамика и межполовые различия распространенности тревоги и депрессии у студентов в 2011 и 2015 гг. (в 2003 г. данный показатель не исследовался). На фоне общих тенденций к снижению тревожных и росту депрессивных расстройств сохраняется тенденция к большему распространению тревоги в обследованной выборке девушек, при этом наблюдается нивелирование уровня распространенности депрессии, ранее более высокого у юношей. 
Динамика распространенности тревоги

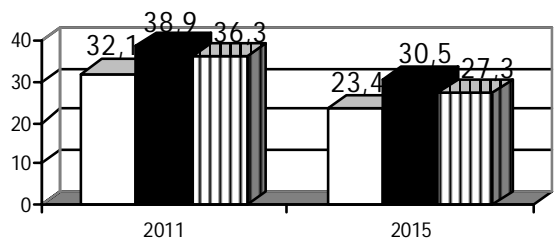

口 юноши $\mathbf{\square}$ девушки $\mathbf{D}$ всего

Динамика распространенности депрессии

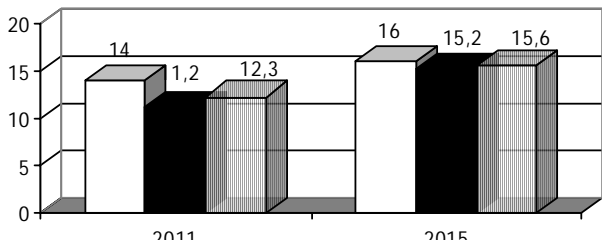

$\square$ юноши $\square$ девушки $\square$ всего

Рисунок 5 - Динамика распространенности тревожной и депрессивной симптоматики среди студентов, \%

Тревожно-депрессивные расстройства высоко распространены среди первокурсников и достигают максимума на II курсе (тревога - 30,5\%, депрессия $18,0 \%)$, с III курса, напротив, неуклонно снижаются (среди пятикурсников и магистрантов распространенность тревоги $-21,2 \%$, депрессии - 12,7\%). Тревожно-депрессивная симптоматика максимально выражена среди прибывших на учебу жителей районов Томской области (тревога - 29,5\%, депрессия $19,5 \%)$, минимально проявляется среди студентовтомичей.

\section{ЗАКЮЧЕНИЕ}

В рейтинге самооценки студентами наиболее актуальных проблем группа, относящаяся к компетенции психиатрической и наркологической службы (химические и нехимические аддикции, невротические состояния), охватывает $27,6 \%$ и занимает второе место. Она уступает лишь проблемам социальной компетенции $(37,3 \%)$ и существенно опережает компетенции культурологическую $(14,4 \%)$, психологическую $(12,4 \%)$, соматической медицины $(4,6 \%)$ и правовую $(3,7 \%)$. В значительной степени такое распределение обусловлено ростом озабоченности студентов проблемой нехимических, виртуальных аддикций.

Распространенность табакокурения среди студентов в исследованиях 2011 и 2015 гг. достаточно стабильна по уровню, половой структуре и мотивировкам. Учитывая, что за данный период произошло выраженное ужесточение законодательства касательно потребления табака, факт стабильности показателей уровня и структуры табакокурения у студентов ожидаемо свидетельствует о неэффективности запретительной политики и попыток стигматизации потребителей.
Необходима переориентация здравоохраненческой и психолого-психотерапевтической стратегии на формирование привлекательности и расширение возможностей здорового образа жизни.

Уровень злоупотребления алкоголем в группе студенческой молодежи уменьшается с 2003 г., однако ведущую роль в данном снижении играют студенты-юноши. Неуклонно продолжается процесс «феминизации» группы злоупотребляющих. Другими важными тенденциями являются возрастание значения алкоголя как своеобразного «адаптогена» (средства ухода от проблем и скуки) и соответствующее снижение влияния социума на студенческую алкоголизацию. При этом речь идет и о макро(снижение значимости традиционной мотивировки), и о микросоциуме (снижение значимости мотивировки субмиссивной).

Динамика ситуации с употреблением наркотиков у студентов нестабильна - как нестабилен и сам нелегальный рынок. Наряду с достоверным снижением уровня выявленного у студентов опыта наркопотребления достоверно возросла обеспокоенность студентов данной проблемой (при столь же достоверном снижении обеспокоенности проблемой алкоголизации). Актуальными являются тенденции феминизации потребителей и динамики мотивировок потребления (снижение значимости субмиссивной и рост атарактической). Исходя из этого, необходима смена парадигмы вмешательств - отход от принципов «обучения навыкам противодействия наркогенному окружению» (одна из основных концепций профилактики в конце XX века) и переход к обучению навыкам повышения стрессоустойчивости $[2,4,5]$.

Тревожно-депрессивные расстройства, имеющие как самостоятельное значение, так и способствующие формированию, поддержанию и рецидивированию расстройств аддиктивных, сохраняют значительный и относительно стабильный уровень распространенности среди студентов. При этом наблюдаемые незначительное снижение уровня тревожных расстройств за счет юношей и незначительный рост депрессий за счет девушек, наряду с выявленной феминизацией наркотизма, обусловливают необходимость разработки и проведения отдельных мероприятий по охране здоровья девушек в вузах. Возможности для дифференцирования, обеспечения адресности превентивных программ могут быть реализованы также с учетом возрастного и миграционного факторов. В качестве основы таких программ предлагается когнитивно-поведенческая копинг-профилактика [9], охватывающая психологические причины и способы реагирования (в том числе аддиктивного и невротического) на сложные жизненные ситуации, выступающие в виде психострессоров.

\section{КОНФЛИКТ ИНТЕРЕСОВ}

Авторы заявляют об отсутствии конфликта интересов в связи с публикацией данной статьи. 


\section{ИСТОЧНИК ФИНАНСИРОВАНИЯ}

В статье приведены результаты исследования, выполненного по Договору № 06/СГ13-323/15У, проект «Проведение социологического опроса по теме «Формирование здорового образа жизни студентов вузов, расположенных на территории Томской области» (Заказчик: Администрация Томской области, 2015).

\section{СООТВЕТСТВИЕ ПРИНЦИПАМ ЭТИКИ}

Работа соответствует этическим стандартам, разработанным в соответствии с Хельсинской декларацией ВМА (протокол заседания локального этического комитета НИИ психического здоровья № 36 от 25 октября 2010 г., дело № 36/1.2010).

\section{ЛИТЕРАТУРА}

1. Аксенов М.М., Семке В.Я., Ветлугина Т.П., Белокрылова М.Ф., Гуткевич Е.В., Иванова С.А., Никитина В.Б., Епанчинцева Е.М. Клиническая динамика пограничных нервнопсихических расстройств. Сибирский вестник психиатрии и наркологии. 2006; 3 (42): 13-16.

2. Аксенов М.М., Гычев А.В., Белокрылова М.Ф., Семке В.Я., Ветлугина Т.П., Никитина В.Б., Перчаткина О.Э., Рудницкий В.А., Левчук Л.А., Костин А.К. Стрессоустойчивость и дезадаптация при непсихотических психических расстройствах (Итоги комплексной темы НИР ФГБУ «НИИПЗ СО РАМН, 2009-2012 гг.). Сибирский вестник психиатрии и наркологии. 2013; 4: 11-17.

3. Бохан Н.А., Благов Л.Н., Кургак Д.И. Коморбидность опиоидной наркомании и алкоголизма у больных молодого возраста: клинические варианты двойного диагноза. Журнал неврологии и психиатрии им. С.С. Корсакова. 2012; 112 (52): $17-23$.

4. Бохан Н.А., Воеводин И.В. Организационные основы медико-психологической помощи студентам вузов. Сибирский вестник психиатрии и наркологии. 2015; 1 (86): 14-17.

5. Бохан Н.А., Воеводин И.В., Асланбекова Н.В. Динамика аддиктивных расстройств у студентов и возможности ее отражения в программах по психопрофилактике. Журнал неврологии и психиатрии им. С.С. Корсакова. 2014; 114 (52): 29-32.

6. Бохан Н.А., Воеводин И.В., Иванкина Л.И. Динамика структуры аддиктивного поведения среди студентов технического вуза за период 1998-2001 гг. Сибирский вестник психиатрии и наркологии. 2001; 4: 49-51.

7. Бохан Н.А., Мандель А.И., Трефилова Л.Л. Наркологическая ситуация в Томской области в сравнении с другими регионами Сибирского федерального округа в 2000-2003 гг. Сибирский вестник психиатрии и наркологии. 2005; 2: 4547.
8. Бухановский А.О., Солдаткин В.А., Мавани Д.Ч., Дьяченко А.В. Компьютерная зависимость: расстройство, которого пока нет в классификациях (обзор зарубежной литературы). Российский психиатрический журнал. 2012; 1: 21-29.

9. Воеводин И.В., Бохан Н.А. Когнитивно-поведенческая копинг-профилактика аддиктивных и аффективных состояний у студентов (новый подход к оценке иррациональных когнитивных установок и копинга). Обозрение психиатрии и медииинской психологии им. В.М. Бехтерева. 2015; 2: 4250.

10. Воеводин И.В., Бохан Н.А., Аболонин А.Ф., Белокрылов И.И., Назарова И.А. Структура, динамика и психологические характеристики мотивировок употребления психоактивных веществ у учащихся высших и средних учебных заведений. Обозрение психиатрии и медииинской психологии имени В.М. Бехтерева. 2014; 4: 37-42.

11. Егоров А.Ю., Цыганков Б.Д., Малыгин В.Л. Патологическое влечение к азартной игре как модель нехимической зависимости. Журнал неврологии и психиатрии им. С.С. Корсакова. 2006; 106 (5): 63-70.

12. Иванец Н.Н., Киржанова В.В., Борисова Е.В., Зенцова Н.И. Проблема употребления наркотиков среди молодежи и пути ее решения. Вопросы наркологии. 2010; 3: 67-73.

13. Иванов В.П. О роли высшей школы в реализации государственной антинаркотической политики. Наркология. 2010; 4: 3-6.

14. Корчагина Г.А., Фадеева Е.В. Порядок организации и осуществления профилактики потребления психоактивных веществ без назначения врача. Вопросы наркологии. 2015; 3 : $107-109$.

15. Москвитин П.Н. Изменение аддиктивной мотивировки у детей и подростков в процессе первичной профилактики. Сибирский вестник психиатрии и наркологии. 2011; 6: 3638.

16. Патрикеева О.Н., Овчинников А.А., Соловьева И.Г. Мотивационный профиль потребителей синтетических каннабиноидов. Неврологический вестник им. В.М. Бехтерева. 2015 XLVII (2): 47-51.

17. Семке В.Я., Гуткевич Е.В., Иванова С.А. Психосоциальные и биологические факторы психической дезадаптации (на модели невротических расстройств). Томск: Иван Федоров, 2008: 204.

18. Lammers J., Kuntsche E., Engels R., Wiers R.W., Kleinjan M. Mediational relations of substance use risk profiles, alcoholrelated outcomes, and drinking motives among young adolescents in the Netherlands. Drug and Alcohol Dependence. 2013; 133 (2): 571-579.

Поступила в редакцию 03.04.2017 Утверждена к печати 26.06.2017

Бохан Николай Александрович, д.м.н., проф., академик РАН, директор НИИ психического здоровья, заведующий кафедрой психиатрии, наркологии и психотерапии СибГМУ.

Воеводин Иван Валерьевич, к.м.н., с.н.с. отделения аддиктивных состояний, доцент кафедры социальной работы философского факультета Лукьянова Наталия Александровна, д-р философ. наук, заведующая кафедрой социальных коммуникаций ТПУ.

Пушкаренко Алексей Борисович, начальник департамента по инновационной деятельности Администрации Томской области.

Воеводин Иван Валерьевич, i_voevodin@list.ru 
УДК 616.891.6:616.895.4:616.89-008.441.13:616.89-008.441.33:65.012.124-028.51:378.17-057.875(571.16)

For citation: Bokhan N.A., Voevodin I.V., Lukiyanova N.A., Pushkarenko A.B. Addictive, anxiety, and depressive disorders among students of the Tomsk Region: dynamics, gender, age, and migration aspects. Siberian Herald of Psychiatry and Addiction Psychiatry. 2017; 3 (96): 38—45. https://doi.org/10.26617/1810-3111-2017-3(96)-38-45

\title{
Addictive, anxiety, and depressive disorders among students of the Tomsk Region: dynamics, gender, age, and migration aspects
}

\author{
Bokhan N.A. ${ }^{1,2}$, Voevodin I.V. ${ }^{1,3}$, Lukiyanova N.A. ${ }^{4}$, Pushkarenko A.B. ${ }^{5}$ \\ ${ }^{1}$ Mental Health Research Institute, Tomsk National Research Medical Center, Russian Academy of Sciences \\ Aleutskaya Street 4, 634014, Tomsk, Russian Federation \\ 2 Siberian State Medical University \\ Moskovsky Trakt 2, 634050, Tomsk, Russian Federation \\ ${ }^{3}$ National Research Tomsk State University \\ Lenin Avenue 36, 634050, Tomsk, Russian Federation \\ ${ }^{4}$ National Research Tomsk Polytechnic University \\ Lenin Avenue 30, 634050, Tomsk, Russian Federation \\ ${ }^{5}$ Administration of the Tomsk Region \\ Lenin Square 6, 634050, Tomsk, Russian Federation
}

\section{ABSTRACT}

The aim of this study was to assess current status and dynamics of mental health of university students (prevalence of addictive, anxiety, and depressive disorders). Material and Methods. We analyzed the results of three studies by the method of anonymous questionnaire survey (2015, 2011 and 2003) and examined 22060, 669, and 657 persons, respectively. Results. In 2015, tobacco smoking prevalence among students was $34.8 \%$, alcohol abuse $-19.6 \%$, experience of drug use $-10.6 \%$, anxiety $-27.3 \%$, depression $-15.6 \%$. Leading trends of dynamics were feminization of drug and alcohol addictions, decrease of significance of submissive motivation and increase of significance of ataractic motivation of psychoactive substances use. This justifies differentiated approaches to prevention of addictions, anxiety, and depression in the universities.

Keywords: students, mental health, substances use, anxiety, depression.

\section{REFERENCES}

1. Aksyonov M.M., Semke V.Ya., Vetlugina T. P., Belokrylova M.F., Gutkevich E.V., Ivanova S.A., Nikitina V.B., Epanchintseva E.M. Clinical dynamic of borderline neuro-mental disorders. Sibirskiy vestnik psikhiatrii i narkologii - Siberian Herald of Psychiatry and Addiction Psychiatry. 2006; 3 (42): 13-16.

2. Aksenov M.M., Gychev A.V., Belokrylova M.F., Semke V.Ya., Vetlugina T.P., Nikitina V.B., Perchatkina O.E., Rudnitsky V.A., Levchuk L.A., Kostin A.K. Stressoustoychivost' i dezadaptatsiya pri nepsikhoticheskikh psikhicheskikh rasstroystvakh (Itogi kompleksnoy temy NIR FGBU «NIIPZ» SO RAMN, 2009-2012 gg.) [Stress resistance and desadaptation in non-psychotic mental disorders (results of complex theme of research work of Mental Health Research Institute SB RAMSci, 2009-2012)]. Sibirskiy vestnik psikhiatrii i narkologii - Siberian Herald of Psychiatry and Addiction Psychiatry. 2013; 4: 11-17 (in Russian).

3. Bokhan N.A., Blagov L.N., Kurgak D.I. Komorbidnost' opioidnoy narkomanii i alkogolizma u bol'nykh molodogo vozrasta: klinicheskie varianty dvoynogo diagnoza [Comorbidity of opioid addiction and alcoholism in patients of young age: clinical variants of the double diagnosis]. Zhurnal nevrologii i psikhiatrii im. S.S. Korsakova - S.S. Korsakov Journal of Neurology and Psychiatry. 2012; 112 (5-2): 17-23 (in Russian)

4. Bokhan N.A., Voevodin I.V. Organizatsionnye osnovy medikopsikhologicheskoy pomoshchi studentam vuzov [Organizational bases of medico-psychological care for university students]. Sibirskiy vestnik psikhiatrii i narkologii - Siberian Herald of Psychiatry and Addiction Psychiatry. 2015; 1 (86): 14-17 (in Russian).

5. Bokhan N.A., Voevodin I.V., Aslanbekova N.V. Dinamika addiktivnykh rasstroystv u studentov i vozmozhnosti ee otrazheniya v programmakh po psikhoprofilaktike [The dynamics of addictions in students and possibilities of reflecting it in psychorehabilitative programs]. Zhurnal nevrologii i psikhiatrii im. S.S. Korsakova - S.S. Korsakov Journal of Neurology and Psychiatry. 2014; 114 (5-2): 29-32 (in Russian).

6. Bokhan N.A., Voevodin I.V., Ivankina L.I. Dinamika struktury addiktivnogo povedeniya sredi studentov tekhnicheskogo vuza za period 1998-2001 gg [Dynamics of the structure of addictive behaviour among students of technical universities for the period 1998-2001]. Sibirskiy vestnik psikhiatrii i narkologii - Siberian Herald of Psychiatry and Addiction Psychiatry. 2001; 4: 49-51 (in Russian).

7. Bokhan N.A., Mandel A.I., Trefilova L.L. Narkologicheskaya situatsiya $\mathrm{v}$ Tomskoy oblasti $\mathrm{v}$ sravnenii $\mathrm{s}$ drugimi regionami Sibirskogo federal'nogo okruga v 2000-2003 gg [Addictological situation in Tomsk district as compared with other regions of Siberian Federal okrug in 2000-2003]. Sibirskiy vestnik psikhiatrii i narkologii - Siberian Herald of Psychiatry and Addiction Psychiatry. 2005; 2: 45-47 (in Russian).

8. Bukhanovsky A.O., Soldatkin V.A., Mavani D.Ch., Dyachenko A.V. Komp'yuternaya zavisimost': rasstroystvo, kotorogo poka net v klassifikatsiyakh (obzor zarubezhnoy literatury) [Computer addiction: a disorder not yet included in the present classification system (review of foreign literature)] Rossiiskii psikhiatricheskii zhurnal Russian Journal of Psychiatry]. 2012; 1: 21-29 (in Russian).

9. Voevodin I.V., Bokhan N.A. Kognitivno-povedencheskaya koping-profilaktika addiktivnykh i affektivnykh sostoyaniy u studentov (novyy podkhod $\mathrm{k}$ otsenke irratsional'nykh kognitivnykh ustanovok i kopinga) [Cognitive-behavioural copingprevention of addictive and affective disorders among the students (new approach to evaluation of irrational cognitions and coping)]. Obozrenie psikhiatrii i meditsinskoy psihologii imeni V.M. Bekhtereva - V.M. Bekhterev Review of Psychiatry and Medical Psychology. 2015; 2: 42-50 (in Russian).

10. Voevodin I.V., Bokhan N.A., Abolonin A.F., Belokrylov I.I., Nazarova I.A. Struktura, dinamika i psikhologicheskie kharakteristiki motivirovok upotrebleniya psikhoaktivnykh veshchestv u uchashchikhsya vysshikh i srednikh uchebnykh zavedeniy [Structure, dynamics, and psychological characteristics of substance use motivation among the students of high and secondary school]. Obozrenie psikhiatrii i meditsinskoy psihologii imeni V.M. Bekhtereva - V.M. Bekhterev Review of Psychiatry and Medical Psychology. 2014; 4: 37-42 (in Russian).

11. Egorov A.Iu., Tsygankov B.D., Malygin V.L. Patologicheskoe vlechenie $\mathrm{k}$ azartnoy igre kak model' nekhimicheskoy zavisimosti [Pathological gambling as a model of non-chemical dependen- 
cy]. Zhurnal nevrologii i psikhiatrii im. S.S. Korsakova S.S. Korsakov Journal of Neurology and Psychiatry. 2006; 106 (5): 63-70 (in Russian).

12. Ivanets N.N., Kirzhanova V.V., Borisova E.V., Zentsova N.I. Problema upotrebleniya narkotikov sredi molodezhi i puti ee resheniya [Drug abuse among students - the ways of solution]. Voprosy narkologii - Journal of Addiction Problems. 2010; 3: 67-73 (in Russian).

13. Ivanov V.P. O roli vysshey shkoly v realizatsii gosudarstvennoy antinarkoticheskoy politiki [Significance of higher school in realization of state antinarcotical politics]. Narkologiya - Narcology. 2010; 4: 3-6 (in Russian).

14. Korchagina G.A., Fadeeva E.V. Poryadok organizatsii i osushchestvleniya profilaktiki potrebleniya psikhoaktivnykh veshchestv bez naznacheniya vracha [The process of organizing and implementing prevention of psychoactive drug consumption without a doctor's prescription]. Voprosy narkologii - Journal of Addiction Problems. 2015; 3: 107-109 (in Russian).

15. Moskvitin P.N. Izmenenie addiktivnoy motivirovki u detey i podrostkov $\mathrm{v}$ protsesse pervichnoy profilaktiki [Change of addiction motivations in children and adolescents in the process of primary prophylaxis]. Sibirskiy vestnik psikhiatrii i narkologii -
Siberian Herald of Psychiatry and Addiction Psychiatry. 2011; 6: 36-38 (in Russian).

16. Patrikeeva O. N., Ovchinnikov A. A., Solovieva I. G. Motivatsionnyy profil' potrebiteley sinteticheskikh kannabinoidov [Motivational profile of consumers of synthetic cannabinoids]. Nevrologicheskii vestnik imeni V.M. Bekhtereva - Neurological Bulletin. V.M. Bekhterev Journal. 2015; XLVII (2): 47-51 (in Russian).

17. Semke V.Ya., Gutkevich E.V., Ivanova S.A. Psikhosotsial'nye i biologicheskie faktory psikhicheskoy dezadaptatsii (na modeli nevroticheskikh rasstroystv).[Psychosocial and biological factors of mental disadaptation (according to model of neurotic disorders)]. Tomsk: Ivan Fedorov, 2008: 204 (in Russian).

18. Lammers J., Kuntsche E., Engels R., Wiers R.W., Kleinjan M. Mediational relations of substance use risk profiles, alcoholrelated outcomes, and drinking motives among young adolescents in the Netherlands. Drug and Alcohol Dependence. 2013; 133 (2). 571-579.

Received April 03.2017 Accepted June 26.2017

Bokhan Nikolay A., MD, Prof., academician of RAS, Director of Mental Health Research Institute, Tomsk National Research Medical Center, Russian Academy of Sciences, Head of Psychiatry, Addiction Psychiatry and Psychotherapy Department of SibSMU, Tomsk, Russian Federation.

Voevodin Ivan V., PhD, senior researcher of Addictive States Department, Mental Health Research Institute, Tomsk National Research Medical Center, Russian Academy of Sciences; lecturer of Social Work Department of Philosophy Faculty, National Research Tomsk State University, Tomsk, Russian Federation.

Lukiyanova Natalia A., Doctor of Philosophy, Head of Social Communications Department of Tomsk Polytechnic University, Tomsk, Russian Federation.

Pushkarenko Alexey B., Head of Department on Innovative Activities of the Administration of the Tomsk Region, Tomsk, Russian Federation.

Voevodin Ivan V., i_voevodin@list.ru 